\title{
Um Processo de Desenvolvimento de Software para o Ensino Técnico baseado em uma Fábrica de Software Escola
}

\author{
Giovanna Lorena R. dos Santos ${ }^{1}$, Edmilson B. Campos Neto ${ }^{1}$ \\ ${ }^{1}$ IFRN, Campus Natal-Zona Norte, Natal/RN, Brasil \\ giovanna.lorena@academico.ifrn.edu.br, edmilson.campos@ifrn.edu.br
}

\begin{abstract}
Resumo. Este trabalho propõe um processo de desenvolvimento de software para implementação de demandas de uma fábrica de software escola em ambiente acadêmico. A metodologia proposta tem como base um modelo iterativo-incremental distribuídos em fases, com a inserção de atividades inspiradas em metodologias ágeis e ferramentas de modelos de negócios. O processo foi aplicado como metodologia prática de ensino em um curso de nível técnico.
\end{abstract}

\section{Introdução}

A formação de desenvolvedores aptos a trabalhar em equipes e seguir metodologias de desenvolvimento é um dos maiores desafios do ensino de engenheira de software. Em função das especificidades do meio acadêmico, - tais como o nível de formação (técnica, graduação); a distribuição da carga horária destinada ao ensino e prática de Processos de Desenvolvimento de Software (PDS) nos currículos dos cursos (semestral, anual); os recursos tecnológicos oferecidos aos discentes; e a natureza dos sistemas desenvolvidos (móveis, distribuídos etc.), - é crucial a adaptação dos processos existentes para a utilização no ambiente acadêmico. Compreender PDS é fundamental para definir uma metodologia para atividades, ações e tarefas por meio das quais um produto de software é desenvolvido, visando otimizar os resultados da equipe (MALIK, 2008).

Ao encontro dessa problemática, a ideia de uma Fábrica de Software Escola (FaSEs) (CAMPOS NETO et al., 2017; FERNANDES, 2015) pode ser uma forma inovadora de aliar teoria e prática visando uma melhor experiência de aprendizado para os alunos. Nessa perspectiva, uma FaSEs foi implantada em uma instituição de ensino profissionalizante com o intuito de possibilitar aos alunos a aplicação dos conhecimentos das disciplinas técnicas trabalhadas em sala de aula, para que possam criar soluções de software para demandas da comunidade acadêmica ou industrial. Entretanto, é essencial que esse projeto conte com um PDS que corresponda às suas demandas e necessidades. Diante disso, este trabalho tem como objetivo geral a elaboração de um PDS, baseado em metodologias difundidas na área, que se adeque a essa realidade do projeto citado, para que os alunos dessa instituição possam ter uma vivência que lhes proporcione as condições necessárias para se tornarem profissionais aptos a trabalhar no desenvolvimento de software.

\section{Estado-da-arte sobre PDSs em Ambiente Acadêmico}

Alguns trabalhos já mapearam técnicas de ensino de engenharia de software, tal como em Santos et al. (2014), mas não focaram em identificar processos de desenvolvimento de software para o ambiente acadêmico. Nesse sentido, esse trabalho realizou um mapeamento sistemático baseado nas diretrizes de KITCHENHAM et al. (2014), com o propósito de identificar as metodologias de processos de desenvolvimento de software que estão sendo propostas e/ou utilizadas em ambientes acadêmicos.

Para seleção dos trabalhos nesse mapeamento, realizamos uma busca manual nos principais veículos de publicações da área de ensino e computação no Brasil. Para tanto, buscamos trabalhos utilizando a chave de busca "processo de desenvolvimento de software 
VII Congresso Brasileiro de Informática na Educação (CBIE 2018)

Anais do XXIX Simpósio Brasileiro de Informática na Educação (SBIE 2018)

AND ensino", nos anais dos seguintes veículos: Simpósio Brasileiro de Informática na Educação (SBIE); Workshop de Informática na Escola (WIE); Workshop sobre Educação em Informática (WEI); Revista Novas Tecnologias da Informação (RENOTE); Revista Brasileira de Informática na Educação (RBIE); e HOLOS. Os eventos foram escolhidos baseados na relevância acadêmica na área de ensino de informática.

Como resultado desse mapeamento sistemático, após a realização da busca manual, foram selecionados oito artigos a serem discutidos neste trabalho. As informações gerais acerca desses artigos estão descritas na Tabela 1.

Tabela 1 - Descrição dos trabalhos selecionados.

\begin{tabular}{|l|l|l|l|}
\hline ID & Título & Evento & Ano \\
\hline P1 & $\begin{array}{l}\text { Modelo Inclusivo de Desenvolvimento e Avaliação de Objetos de Aprendiza- } \\
\text { gem Acessíveis voltados para o Ensino Superior em Computação }\end{array}$ & SBIE & 2016 \\
\hline P2 & PAS: Uma Proposta de Processo para o CEFET-RN/DATINF & HOLOS & 2006 \\
\hline P3 & $\begin{array}{l}\text { Processo de Desenvolvimento do Jogo Sério Missão Aedes: relações entre ob- } \\
\text { jetivos pedagógicos, ludicidade e implicações de design }\end{array}$ & SBIE & 2016 \\
\hline P4 & PDS Educacional: proposta e experimentação & RENOTE & 2005 \\
\hline P5 & Aprendizagem Baseado em Metodologias Ágeis e Scaffoldings & RBIE & 2010 \\
\hline P6 & PDS-E: Em direção a um PDS Educacional & WIE & 2005 \\
\hline P7 & SimpleWayProcess: Da Academia à Indústria de Software & WEI & 2012 \\
\hline P8 & ENgAGED: Um Processo de Desenvolvimento de Jogos & SBIE & 2016 \\
\hline
\end{tabular}

QP1. Em que metodologias o processo se baseia?

Para elaborarem os processos sugeridos, os trabalhos tiveram como base algumas metodologias de PDS já reconhecidas e utilizadas. Entre elas, foram escolhidas 6 para representação gráfica (Figura 1.a), tendo em vista que se constituem as mais reconhecidas. Apenas um dos processos não especificou qual metodologia utilizou, enquanto a maioria utilizou mais de um deles. Os métodos mais utilizados foram o RUP e o XP. Outras metodologias foram utilizadas: Scrum, Behaviour-Driven Development (BDD), easYProcess (YP) e Analysis, Design, Development, Implementation and Evaluation (ADDIE). Este último não é um PDS, mas um modelo de Design Instrucional, utilizado pelos trabalhos que propuseram processos para o desenvolvimento de jogos educacionais.

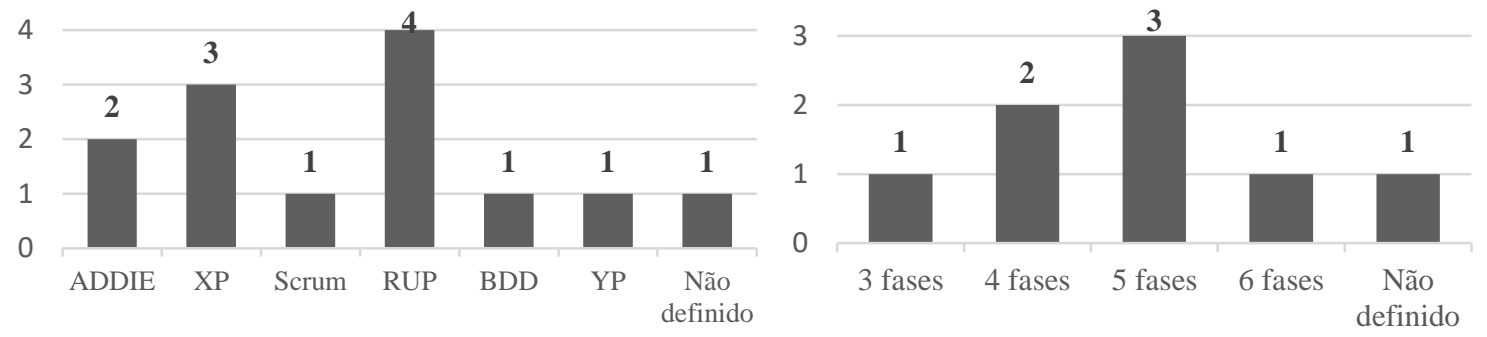

Figura 1 - (a) Processos por metodologias utilizadas e (b) fases por processo.

QP2. Qual a natureza de utilização do processo?

Nós observamos que a maioria dos PDS propostos na literatura são específicos para produção de software de cunho educacional, apenas com algumas diferenças de termos e conceitos. Nós dividimos os processos analisados em quatro classificações quanto a natureza de sua utilização: (i) não definida, (ii) jogos educacionais, (iii) objetos de aprendizagem e (iv) software educacional, sendo que cada uma corresponde a $25 \%$ dos trabalhos. Dessa forma, observa-se que $75 \%$ correspondem à natureza de cunho educacional e apenas $25 \%$ não define a natureza de utilização. 
VII Congresso Brasileiro de Informática na Educação (CBIE 2018)

Anais do XXIX Simpósio Brasileiro de Informática na Educação (SBIE 2018)

\section{QP3. Qual o nível de formação do curso em que o processo foi desenvolvido?}

A maioria dos processos foram produzidos em ambiente de cursos de bacharelado. Apenas 2 dos processos foram produzidos e utilizados no curso de Tecnologia em Análise e Desenvolvimento de Sistemas. Esses dois últimos são, na verdade, os que mais se aproximam à proposta deste trabalho. Outros 2 processos foram produzidos por alunos da graduação, mas com o intuito de serem utilizados por uma comunidade externa e não em ambiente acadêmico. Ademais, apenas 1 especificou que o processo seria utilizado dentro de uma disciplina do curso. Entretanto, nenhum dos processos foi produzido/utilizado para o ensino técnico profissionalizante.

QP4. Quais os detalhes da estrutura do processo?

Conforme apresentado na Figura 1.b, os processos estudados propõem predominantemente de 4 a 5 fases. Apenas 2 sugerem 3 e 6 fases, sendo que um outro não define quantidade fases. Genericamente, as primeiras fases são de definição do projeto, levantamento de requisitos e definição de papéis, as intermediárias, são de construção do produto e, as últimas, fases de teste e implementação. Apesar dessa visão geral ser perceptível, cada processo tem suas diferenças de acordo com as demandas a quais se propõe atender. Em se tratando de atores e atividades, poucos trabalhos descrevem seus processos nesse nível de detalhamento. Com raras exceções, tal qual é feito no trabalho P4.

Diante das discussões, entende-se que os PDSs encontrados são, em sua maioria, voltados à produção de software de natureza educacional e, mesmo os que não o são, por serem propostos para ambientes de nível superior, não contemplam a necessidade exposta anteriormente neste trabalho. Dessa forma, faz-se ideal a elaboração de um processo que possa ser disponibilizado para o uso por professores do ensino técnico, contribuindo com a formação de profissionais aptos a desenvolver sistemas na indústria.

\section{FaSEs Process}

Esta seção apresenta a nossa proposta de PDS para proporcionar uma experiência efetiva no aprendizado de engenharia de software e ao mesmo tempo propiciar um fluxo mais iterativo para uma fábrica de software escola. O processo proposto baseia-se em um modelo iterativo-incremental distribuídos em fases, com a inserção de atividades inspiradas em metodologias ágeis, como Scrum, e ferramentas de modelos de negócios, como business model canvas. Ao todo, quatro tipos de estruturas principais formam o processo: fases, atividades, tarefas e artefatos. Cada fase é dividida em atividades, as quais são divididas em tarefas, que, por sua vez, geram artefatos. Também foram definidos guias para os artefatos gerados nas tarefas. Esses guias podem ser exemplos ou templates e alguns possuem indicações de ferramentas e de tutoriais. $\mathrm{O}$ processo proposto foi dividido em 4 fases: Iniciação, na qual busca-se responder à pergunta "O que será feito?"; Elaboração, na qual a pergunta é "Como será feito?"; Construção, que corresponde ao desenvolvimento real do projeto descrito e elaborado anteriormente; e Transição, para últimos ajustes e implantação. O processo foi incialmente definido e depois implementado na ferramenta EPF Composer <http://eclipse.org/epf $>$ e disponível ao discente no site $<$ http://fases.ifrn.edu.br/process $>$. Cada fase possui um fluxo de atividades que vinculam atividades presentes nos currículos das disciplinas do currículo do curso objeto de implantação, tais como interação-humano computador, engenharia de software, programação de sistemas para internet, banco de dados e análise projeto orientado a objetos.

Adicionalmente, foram decididos quais os papéis presentes no processo: analista, arquiteto, desenvolvedor, designer (projetista), gerente, stakeholder e testador. Cada um 
VII Congresso Brasileiro de Informática na Educação (CBIE 2018)

Anais do XXIX Simpósio Brasileiro de Informática na Educação (SBIE 2018)

desses papéis desempenha várias tarefas, mas no grupo em sala de aula, o mesmo aluno varia de papel a papel de acordo com a mudança de tarefa, atividade ou fase. Ademais, tendo em vista a carga horária na disciplina do curso em questão, o processo proposto visa reduzir a documentação gerada, mas manter uma documentação que seja suficiente para o controle da sala de aula e que também possa ser adaptável de acordo com a turma e o professor. Na Tabela 2, pode-se observar alguns dos artefatos do processo, bem como em que documento ele foi inspirado, a metodologia de origem e a justificativa para a adaptação ou manutenção do artefato.

Tabela 2 - Inspiração de alguns artefatos do FaSEs Process.

\begin{tabular}{|l|l|l|l|}
\hline \multicolumn{1}{|c|}{ Inspiração } & $\begin{array}{l}\text { Metodologia } \\
\text { de origem }\end{array}$ & \multicolumn{1}{|c|}{$\begin{array}{c}\text { FaSEs } \\
\text { Process }\end{array}$} & \multicolumn{1}{|c|}{ Justificativa } \\
\hline $\begin{array}{l}\text { Documento } \\
\text { de visão }\end{array}$ & OpenUP & Canvas & $\begin{array}{l}\text { O modelo Canvas pode ser feito em sala de aula em 2 horas- } \\
\text { aula e dará aos alunos uma visão geral das características do ne- } \\
\text { gócio do produto escolhido, compreendendo os elementos de } \\
\text { um documento de visão }\end{array}$ \\
\hline $\begin{array}{l}\text { Work items } \\
\text { list }\end{array}$ & OpenUP & $\begin{array}{l}\text { Requisitos ca- } \\
\text { dastrados no } \\
\text { Trello }\end{array}$ & $\begin{array}{l}\text { Esse cadastro pode ser acompanhado de maneira fácil por todos } \\
\text { os integrantes e pelo professor, proporcionando um gerencia- } \\
\text { mento de requisitos até o final do projeto }\end{array}$ \\
\hline $\begin{array}{l}\text { Backlog do } \\
\text { sistema }\end{array}$ & Scrum & $\begin{array}{l}\text { Cadastro de Is- } \\
\text { sues no Git }\end{array}$ & $\begin{array}{l}\text { O conjunto de issues corresponderá ao todo do projeto a ser en- } \\
\text { tregue no final da etapa de construção, esse cadastro servirá } \\
\text { para que haja um gerenciamento a visão do desenvolvimento do } \\
\text { sistema para todos os integrantes }\end{array}$ \\
\hline $\begin{array}{l}\text { Backlog da } \\
\text { Sprint }\end{array}$ & Scrum & $\begin{array}{l}\text { Identificação } \\
\text { das Issues a im- } \\
\text { plementar em } \\
\text { cada Sprint }\end{array}$ & $\begin{array}{l}\text { Essa identificação tornará visível e gerenciável, a todos os inte- } \\
\text { grantes, o que deve ser feito na Sprint em execução e por quem } \\
\text { deve ser feito, permitindo verificar o progresso do desenvolvi- } \\
\text { mento }\end{array}$ \\
\hline Script de teste & OpenUP & $\begin{array}{l}\text { Relatório de } \\
\text { testes }\end{array}$ & $\begin{array}{l}\text { Mesma estrutura mantida, forma simples e sistemática de regis- } \\
\text { trar os resultados dos testes das funcionalidades trabalhadas em } \\
\text { cada Sprint }\end{array}$ \\
\hline $\begin{array}{l}\text { Build } \text { ex- } \\
\text { ecutável }\end{array}$ & Scrum & $\begin{array}{l}\text { Versão do } \\
\text { produto }\end{array}$ & $\begin{array}{l}\text { Artefato gerado ao final de cada Sprint, é um resultado potenci- } \\
\text { almente entregável }\end{array}$ \\
\hline
\end{tabular}

\section{Resultados da Aplicação do Processo no Ensino Técnico}

O FaSEs Process foi desenvolvido para o ambiente acadêmico de uma fábrica de software, tendo como base disciplina de PDS do $4^{\circ}$ período de um curso técnico integrado ao ensino médio. Essa disciplina tem o objetivo de preparar os alunos para trabalhar com desenvolvimento de software de forma eficiente e eficaz, colocando em prática conteúdos ministrados em todas as disciplinas técnicas ministradas ao longo do curso. Diante disso, a ementa da disciplina prevê o desenvolvimento de um projeto mediante a utilização de um PDS. Nesse sentindo, o FaSEs Process possibilita um melhor aproveitamento da interdisciplinaridade no curso, por conter atividades que se conectam com as diferentes disciplinas (conforme visto na Seção 4). Anteriormente, era utilizada uma adaptação do OpenUp para essa prática na disciplina, mas a documentação rigorosa e numerosa se mostrou inviável, tendo em vista a carga horária da disciplina e a própria dinâmica da academia, muito diferente da realidade da indústria. Com o FaSEs Process, manteve-se uma documentação suficiente para avaliação dos alunos e para compreensão do conteúdo do componente curricular, como também os discentes puderam ter uma vivência de metodologias ágeis e dinâmicas diferentes das tradicionais, ampliando suas visões de como o desenvolvimento de software acontece na prática.

Em 2017, enquanto o processo estava sendo modelado, ele foi aplicado para fins de avaliação preliminar em uma turma com 14 alunos que resultou em 3 projetos, que, ao final da disciplina, foram disponibilizados na rede para uso público. Os projetos foram 
VII Congresso Brasileiro de Informática na Educação (CBIE 2018)

Anais do XXIX Simpósio Brasileiro de Informática na Educação (SBIE 2018)

acompanhados por docentes de três disciplinas técnicas e a turma obteve uma média final de 86,07 (média de todos os grupos) com desvio padrão de 10,51. Em 2016, antes da aplicação do FaSEs Process, a média da turma, avaliada com os mesmos critérios, atingiu 73,03 , com desvio padrão de 8,19. Avalia-se que, de forma geral, após a aplicação preliminar do processo, a turma obteve uma melhoria no rendimento que pode ser reflexo de uma maior compreensão do processo e aproveitamento da carga horária para se atingir o objetivo final da disciplina. Em 2018, o processo completo está sendo utilizado em uma nova turma, com 36 alunos, com 7 projetos em desenvolvimento, todos frutos de clientes reais captados pela FaSEs. Uma pesquisa de avaliação prévia foi aplicada com esses 36 alunos para medir o grau de importância que eles atribuem para três características principais do processo. Os resultados foram positivos e estão apresentado na Figura 2.

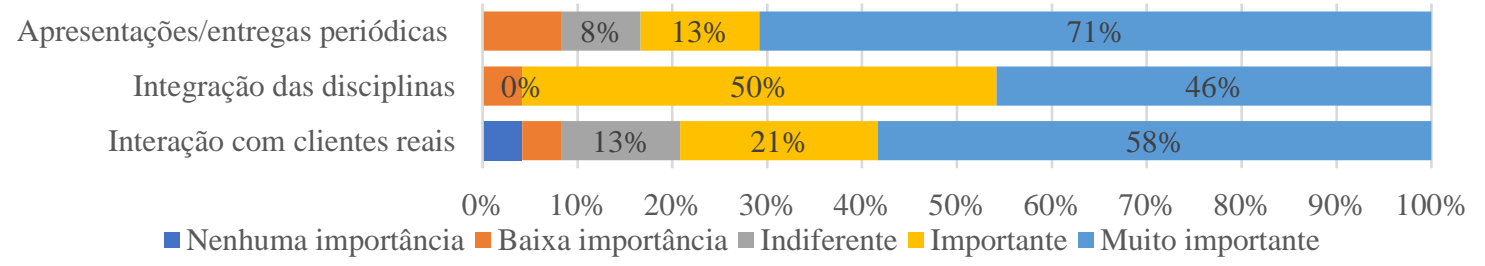

Figura 2 - Importância à formação que os alunos atribuem às atividades do processo.

Ao final do ano letivo, pretende-se avaliar a experiência dos alunos e propor melhorias para o processo, baseado em questionários para medir o retorno do aprendizado com o processo e a satisfação dos clientes/demandantes de soluções.

\section{Conclusão}

Considerando-se a necessidade de um PDS especializado para o ambiente acadêmico do ensino técnico, que atendesse às peculiaridades do curso-alvo, foi realizado o mapeamento sistemático com o intuito de buscar na literatura os PDS para a academia. A maioria dos processos encontrados, entretanto, era voltado ao desenvolvimento de jogos e/ou software educacionais específicos, distintos da nossa realidade. Nessa perspectiva, o FaSEs Process foi criado, com base em metodologias difundidas na área e considerando as condições do ambiente acadêmico - carga horária, nível de formação, recursos tecnológicos oferecidos pela instituição etc. Além disso, o processo foi definido utilizando uma ferramenta padrão para definição de processos, o EPF Composer, e, por fim, tornado público para que seja usado academicamente. Diante disso, conclui-se que as experiências de utilização do FaSEs Process estão sendo bem-sucedidas até o momento e devem ser bem avaliadas ao final do ano letivo de 2018 para verificar sua viabilidade e aderência. Dessa forma, propõe-se como trabalho futuro o refinamento do processo de acordo com o resultado da vivência e da avaliação de sua utilização. Os guias do FaSEs Process também podem ser atualizados com mais exemplos e templates e as descrições dos elementos do processo podem ser revisadas. Todos os trabalhos futuros devem ter o propósito de adequar cada vez mais o processo à realidade acadêmica, visando uma formação efetiva e eficaz, que prepare os discentes para o mercado de trabalho e para indústria.

\section{Referências}

CAMPOS NETO, E. B. LOPES, A. S. B.; NASCIMENTO, D. S. C. Um relato de experiência da implantação de um modelo de fábrica de software escola (FaSEs). In: WEI, 2017, São Paulo.

FERNANDES, A. A.; TEIXEIRA, D. de S. Fábrica de software. São Paulo: Atlas, 2004.

KITCHENHAM, B.; et al. Evidence-based software engineering. ICSE, 2004, DC/USA.

MALIK. Software quality: a practitioner's approach. [S. 1.]: Tata McGraw-Hill Education, 2008.

SANTOS, R. E. et al. Ferramentas, métodos e experiências no ensino de engenharia de software: um mapeamento sistemático. In: SBIE, 2014. 